\title{
Arthur Logan Turner, M.D., LL.D., F.R.C.S.E.
}

THE "passing" on June 6, 1939, of Arthur Logan Turner will be deeply regretted by all those who, irrespective of their nationality, have at heart the best interests of Octology, Laryngology, and Rhinology. Coincidently, they will sympathise with the University of Edinburgh, which has lost one of its most distinguished sons.

In the limited space at my disposal, it must suffice to envisage the personality of the man and the nature and quality of his work as I believe them to have been estimated by his confréres south of the Border.

It is not improbable that a stranger meeting Logan Turner for the first time might have found him reserved and somewhat difficult to approach. But as so often happens in like circumstances, further acquaintance soon proved those features to be a thin armoury which sheltered a kind, very modest, and always sympathetic friend.

Unless my memory be at fault, it was in 1893 when he and I found ourselves amongst the junior members of the recently established "Laryngological Society of London" which, in its ambit, included Rhinology. After a few of its monthly meetings, it became evident that we were particularly interested in inflammatory affections of the frontal sinuses and their possible, local or distant complications. It was a subject which, hitherto, had received little attention from rhinologists because the upper air-cells represented almost unexplored regions of the skull and treatment (sic) of pathological discharge from them was (according to a senior American surgeon) confined to intra-nasal "snipping and spraying-mostly sprays." Hence, and with his usual perspicacity, Logan Turner realised that without a full knowledge of the anatomy of the sinuses, it would be impossible to realise the significance of their clinical manifestations, or to base treatment of them on the ordinary principles of surgery.

With a wealth of skulls available, he was soon able to determine the normal size and configuration of the air-cells, their interrelationships and commoner variations. Meanwhile, his clinic in the Royal Infirmary afforded ample opportunities for determining to what extent symptoms and signs might be modified by the structural factors.

These combined observations, with a number of illustrations, were 
published in October 1901 and entitled The Accessory Sinuses of the Nose, their Surgical Anatomy and the Diagnosis and Treatment of their Inflammatory Affections.

In 1923 he was chosen to deliver the annual "Semon Lecture" (University of London) and, as a born teacher, his confréres were not surprised that he took as his subject "The Advancement of Laryngology and Octology. A Plea for Adequate Training and Closer Co-operation."

With these and the many other services he rendered to our special departments of Medicine, it is not surprising that American and Continental Societies enrolled our friend's name on their lists of Honorary Fellows.

It has always seemed to me that he was one of the few whose contributions on any disease he had studied betrayed an exceptionally ordered mind which enabled him to express his views with a clarity which many of us must have envied.

If, therefore, we bear in mind his personal qualities and the debt our speciality and the Edinburgh School of Medicine owe to him, it would not be extravagant to say of Logan Turner-

"His life was gentle and the elements

So mixed in him, that Nature might stand up

And say to all the world, "This was a man!",

He was elected a Fellow in I905, served on the Council from 1926 to 1929, and as a Vice-President from 1930 to 1933.

H. T. 